\title{
EDUCAÇÃO EM MUSEUS: A INTERAÇÃO COMO EXPERIÊNCIA
}

\author{
Christine Muller \\ CIVILIS/FE/UNICAMP ${ }^{1}$ \\ cmchrismuller50@gmail.com
}

\begin{abstract}
RESUMO
Este trabalho trata da especificidade constitucional da educação em museus, partindo da problemática que essa tipologia educacional tem características em seu funcionamento que a diferenciam de outras modalidades educacionais. Nesta pesquisa, que se articula ao projeto "Preservação do Patrimônio Histórico-Educativo", sob a orientação da Profa. Dra. Maria Cristina Menezes, optou-se por um estudo que possibilitasse a compreensão da mesma e a investigação da interação como experiência. Na sociedade contemporânea, uma das funções do museu é estar ao serviço da sociedade e de seu desenvolvimento. Dessa forma, o papel social concedido ao museu, potencializa-o como um local de comunicação que por sua vez agiliza suas ações educativas, as quais precisam ser refletidas para atrair os públicos variados. Assim, o presente estudo tem como objetivo pesquisar quais processos educacionais são colocados em prática nos museus e compreender os desafios apresentados aos educadores de museus na relação com os visitantes. A educação em museus é uma prática que vem consolidando-se no campo educacional, tanto por uma prática educacional estabelecida a partir das instituições museais, mas também devido ao crescimento do número de trabalhos acadêmicos que se dedicam ao tema. Finalmente, para proceder essa discussão, optou-se neste texto por uma abordagem metodológica articulada a um referencial de pesquisa que buscamos na educação em museus, na nova museologia e na educação patrimonial.
\end{abstract}

Palavras-chave: Educação em museus. Educação patrimonial. Nova museologia.

\section{EDUCATION IN MUSEUMS: THE INTERACTION AS EXPERIENCE}

\begin{abstract}
This paper deals with the constitutional specificity of the education in museums, starting with the problematic that this educational typology has characteristics in its operation that turn it different of other educational modalities. In this research that articulates itself to the project "Preservação do Patrimônio Histórico-Educativo", under orientation of prof. Dr. Maria Cristina Menezes, a study was chosen that would allow its understanding and the interactive investigation as experience. In the contemporary society, one of the functions of the museum is to be at service of the society and its development. In this way, the social role granted to the museum, gives it as a communication site that on its way agilizes its educative actions, that need to be revealed to attract the different public. Thus, the present study aims to search which educational procedures are put in practice in the museums and understand the challenges presented to the museum educators in relation to the visitors. The education in museums is a practice that is becoming consolidated in the educational field as well as by a educational practice established starting from the museum institutions, but also due the increase in the number of academic papers that are devoted to the subject. Finally to proceed this discussion, it was chosen in this text a methodological approach articulated to a research
\end{abstract}

\footnotetext{
1 A pesquisa articula-se ao Projeto "Preservação do Patrimônio Histórico-Educativo: Acervos Escolares de Campinas” sob orientação da Profa. Dra. Maria Cristina Menezes, CIVILIS/FE/UNICAMP.
} 
reference that we seek in the education in museums, in the new museology and in the patrimonial education.

Keywords: Education in museums. Patrimonial education. New museology.

\section{INTRODUÇÃO}

Este trabalho trata da especificidade constitucional da educação em museus, partindo da problemática que essa tipologia educacional tem características em seu funcionamento que a diferenciam de outras modalidades educacionais. Optou-se por um estudo que possibilitasse a compreensão da educação em museus e seus desafios com relação ao público e museus interativos.

Dessa forma, o presente estudo tem como objetivo investigar quais processos educacionais são colocados em prática nos museus interativos e compreender os desafios apresentados aos educadores de museus na relação com os visitantes.

Para proceder essa discussão, optou-se neste texto por uma abordagem metodológica articulada a um referencial de pesquisa que buscamos na educação em museus, na Nova Museologia e na educação patrimonial. Na sociedade contemporânea, uma das funções do museu é estar a serviço da sociedade e de seu desenvolvimento. Dessa forma, o papel social, concedido ao museu, potencializa-o como um local de comunicação que, por sua vez, agiliza suas ações educativas, que precisam ser refletidas para atrair os públicos variados.

Pensar e realizar ações educativas são funções do educador de museu, que necessita compreender os conceitos que atravessam esse espaço.

A educação em museus é uma prática que vem ganhando contornos cada vez mais definidos no campo educacional. Essa definição está relacionada por um lado, a uma crescente prática educacional estabelecida a partir das instituições museais.

No que se relaciona à consolidação da Educação em Museus como campo científico, há pesquisas em três vertentes que se diferenciam conforme os tipos de museus: a arte/educação, a educação patrimonial e a comunicação da ciência.

\section{NOVA MUSEOLOGIA: DEBATES DO SÉCULO XX}

A Nova Museologia possui como proposta refletir sobre os interesses do público em detrimento das virtudes das coleções, como ocorria nos séculos anteriores. No século XVII, apenas viajantes considerados distintos e cientistas tinham o direito de apreciar as coleções e 
os jardins botânicos dos príncipes europeus. A partir de 1700, a Galeria Imperial de Viena, o Palácio Quirinal de Roma e o Escorial da Espanha permitiram que o público entrasse por meio do pagamento de uma taxa, e a Galeria da Corte de Dresden tornou as visitas mais fáceis a partir de 1746. O Asmolean, na Inglaterra, considerado museu público, possibilitava a entrada de especialistas, estudiosos e estudantes universitários, e os museus que dependiam da Igreja só permitiam a entrada de convidados especiais, artistas e elite governante.

O primeiro museu a revolucionar o conceito de relacionamento com o público foi o Louvre, entre 1795 e 1799. Surgiu como resultado da estatização de coleções da realeza e do clero após a Revolução Francesa, e foi aumentando com os saques de guerra de Napoleão. Foi considerado, desdeo início, um "museu do povo", onde qualquer pessoa podia ir sem pagar. Seu objetivo fundamental era educar as pessoas, ou seja, introjetar-lhes os valores burgueses pós-revolução. (BARRETTO, 2000, p. $64)$.

Aproximando-se do século XX, a partir de 1950, os museus tradicionais europeus, cujo modelo tinha se estendido pelo mundo, começaram a ser questionados pelos franceses Georges Bazin, Marcel Evrard e Hugues de Varine- Bohan.

As modificações, no entanto, só se manifestaram na década de 1970, quando houve um clima propício, em virtude da crise que os museus enfrentavam (...). A crise dos museus era resultado, em parte, de uma revisão de conceitos da área de antropologia. Essa ciência tinha- se apoiado durante muitos anos na coleta de evidências da cultura material. (BARRETTO, 2000, p. 62).

Os museus de arte foram os primeiros a questionarem a necessidade de uma maior interação com o público com o objetivo de educar para ver. Na década de 1970, foram iniciadas novas experiências pelo Museu Nacional de Cuba, em Havana, e pelo Museu das Crianças criado numa sala do Museu de Belas Artes do Palais de Longchamp, em Marselha, na França. Após conhecerem as técnicas artísticas, com o auxílio de professores, os visitantes podiam tocar as obras e desenvolver trabalhos manuais, além de debater sobre as obras expostas.

Assim, a mudança no caráter público dos museus, de instituições que armazenavam e estudavam coleções do mundo natural e cultural, para instituições nas quais as necessidades do público visitante têm um papel fundamental, aconteceu de forma mais drástica a partir da segunda metade do século XX. Essas tensões não aconteceram sem resistências e mesmo nos dias atuais suscita intensos debates na comunidade museológica.

O movimento que deu impulso a essas transformações é conhecido no interior da comunidade museológica como movimento da Nova Museologia e teve como foco o questionamento acerca do papel e das responsabilidades das instituições culturais frente às 
transformações e problemas presentes na sociedade. Esse movimento representou novos paradigmas de atuação profissional, responsáveis pela potencialização tanto do acesso de um público mais diversificado aos museus quanto do surgimento de novos modelos e iniciativas institucionais.

Um dos aspectos mais relevantes dessa discussão é abordado por Valente (2008), ao debater as diversas definições propostas para a palavra museu que se deram no interior da comunidade museológica. Assim, Martins (2011) fundamentando-se na autora acima escreve:

[...] é a função de coleta e estudo de coleções ou a função social de educação e comunicação que deve ser a tônica dessa instituição? Essa questão, até os dias atuais não foi respondida e é alvo de inúmeros debates dentro da comunidade. A tendência a uma maior consideração pelas atividades de pesquisa em detrimento das atividades de extroversão e comunicação com os públicos de não cientistas podem ser percebidas em muitas instituições. (MARTINS, 2011, p. 58).

Conforme Valente (2008) essa abordagem múltipla do fenômeno museal, que irá se consolidar com o passar dos anos na medida em que os museus se tornam objeto de estudo das mais diferentes disciplinas, revela uma busca pela identidade institucional.

As discussões a respeito das funções a serem desempenhadas pela instituição, implicadas na definição de museu, também são tributárias em grande medida dos debates empreendidos nas reuniões da comunidade museológica profissional ao longo do século XX. Muitas das preocupações sobre a transformação do papel do público nos museus foram registradas nos documentos produzidos nessas reuniões.

Como consequência, as exposições, as ações educativas e demais atividades educativas voltadas para o público, ganharam um peso e uma relevância cada vez maiores.

Dessa forma, a primeira metade do século XX foi dedicada para ações com o objetivo de democratizar a instituição, ou seja, a abertura ao público geral e o desenvolvimento de seu papel educativo.

Merecem ser sublinhados, como marcos que auxiliam para a estruturação dessa abordagem social, o Seminário Regional da Unesco sobre a Função Educativa dos Museus (Rio de Janeiro, 1958), a $8^{\text {a }}$ e a $9^{\text {a }}$ Conferências Gerais do ICOM, realizadas em Munique (1968) e Paris/Grenoble (1971), a Mesa-Redonda de Santiago do Chile (1972), o I Atelier Internacional da Nova Museologia, ocorrido em Quebec, o Seminário de Oaxtepec, ocorrido na cidade do México (ambos em 1984) e o Seminário de Caracas (1992). 


\section{A NOVA MUSEOLOGIA E A EDUCAÇÃO PATRIMONIAL}

A educação patrimonial centra-se em processos de ensino-aprendizagem do patrimônio. Conforme Merillas (2003) o patrimônio é uma realidade cultural, mas que tem passado por procedimentos (mediante a educação ou pela transmissão) de propriedade, de identidade, de herança e de caracterização de um contexto.

Dentro do ensino do patrimônio, inclui-se os conteúdos "conceituais", "procedimentais" e "atitudinais". De acordo com a autora, os conteúdos "conceituais" referem-se aos conceitos relacionados com o patrimônio ou com as realidades específicas que compreendem (história, arte, geografia, política, etc.); os conteúdos "procedimentais" relacionam-se aos processos vinculados à emissão, recepção e mediação entre o patrimônio cultural e a sociedade. Por último, os conteúdos "atitudinais" centram-se nos comportamentos dos indivíduos ou grupos frente ao patrimônio (em situações de recepção, de transmissão, de apreciação, de valorização, etc.). Estes conhecimentos integram-se, novamente, dentro da sequencia procedimental "conhecer-compreender-respeitar-valorizar-cuidar-apreciartransmitir".

Colocar a ênfase no sujeito que aprende constitui uma das especificidades da educação, frente ao tratamento de outros corpos disciplinares que, como a gestão, o turismo, a política ou a economia, se ocupam mais da intervenção no patrimônio, da emissão ou da própria mensagem. Por isso:

\footnotetext{
ordenarlaensenanzadel patrimônio em función de esse sujeto que aprende, nos permite establecer una estructuración de loscontenidos, de losprocedimientos y de los contextos. En definitiva, permite reorganizar adecuadamentelosprocesos de ensenanza-aprendizajeen torno al patrimônio para que esossujetos que aprendenpuedanconocerlo, comprenderlo, respetarlo, valorarlo, cuidarlo, disfrutarlo y transmitirlo, cualquiera que seasu circunstancia y em lamejor de las condiciones posibles. (MERILLAS, 2003, p. 178-179).
}

Partindo destes pressupostos, inicia-se o processo educativo desde o patrimônio mais individual do aluno (suas recordações, sua memória) para chegar àquele patrimônio mais universal, coincidindo neste transito com as abordagens da história, da política, da economia, etc. Assim, cumpre-se o preceito do patrimônio como memória de um contexto, porém se amplia a noção de contexto, desde a dimensão pessoal até a universal, abordando nesta abertura os processos de identidade individual e coletiva.

Segundo Cepeda e López (2013), as propostas sobre educação patrimonial supõem muita responsabilidade. Devem ser apresentadas com fundamentação teórica e com 
adequação às necessidades dos destinatários. Também, ser inserida a avaliação final sobre a recepção e interação do público.

Dessa forma, a qualidade sustentada pela responsabilidade, profissionalismo e envolvimento é fundamental no trabalho sobre educação patrimonial.

As autoras em questão destacam especialmente a metodologia que, longe de centrarse em interpretações preestabelecidas, permite que o espectador seja livre para trazer suas experiências e construir seu próprio significado.

Da mesma forma podem ser configurados os projetos sobre educação patrimonial em Museus da Educação. O importante é não estar apenas focado nos objetos escolares em si, mas compreender o contexto sócio-cultural em que tais objetos foram produzidos, quais eram as representações vigentes na época, etc. Assim, deve-se levar em consideração:

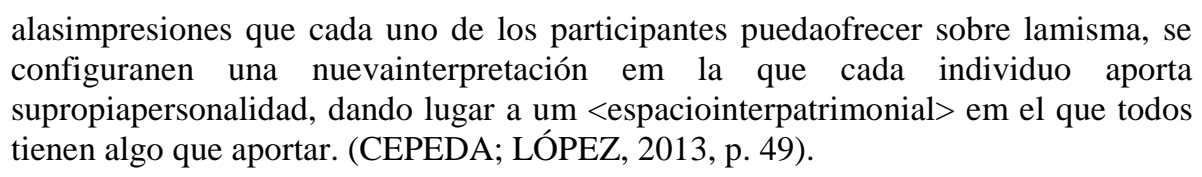

Segundo as autoras, ao discutirmos educação patrimonial é muito importante compreender e tentar suprir as expectativas do público alvo e os objetivos previamente estabelecidos. Dessa forma, é possível alcançar o desenvolvimento de um aprendizado significativo, fundamental para que os novos conceitos não sejam esquecidos e sim que se incorporem ativamente à cultura e vida dos que participam.

Por outra parte, a compreensão do patrimônio de um ponto de vista educativo nos permite abordar todos aqueles processos que se geram em torno dele, desde a implicação emotiva (desenhos, recordações, afetos...), até a cognição (observação, análise, descobrimento...). Insistir nos conteúdos procedimentais é resultado de uma visão educativa, e se diferencia substancialmente daquelas ordenações centradas nos conteúdos conceituais próprios de modelos de corte historicista.

Enfatizamos a importância da avaliação e posterior reflexão sobre os resultados obtidos. Dessa forma, é possível realizar um modelo de trabalho bem desenvolvido, centrado e sério. 


\section{EDUCAÇÃO EM MUSEUS: DESAFIOS NA RELAÇÃO PÚBLICO E MUSEUS INTERATIVOS}

Baseando-se nas pesquisas realizadas por Dexter Lord e Lord (2006) as autoras Alderoqui e Pedersoli (2011) apresentam a noção de que as exposições transmitem sentidos e significados que acreditam ser importantes para os visitantes, com o objetivo de atingir de alguma forma seus interesses, comportamentos ou concepções para que de alguma forma ocorra uma mudança, aprendizagem, emoção, etc.

Dessa forma, gestão de um projeto de design e estruturação de exposições exige uma equipe constituída por especialistas em design e museografia, conservação e educação, edição e produção de textos, em conteúdo, produção e montagem, produção multimídia, etc.

\footnotetext{
Los procesos de disenosontrabajosen espiral, que avanzanyregresan a lospuntos de inicio parareconfirmar lãs primerashipótesis o desecharlas, hasta que lasideasfuertes van tomando cuerpo. Este modo de pensar eldiseno de lãs exposiciones supera los esquemas lineales de pasos consecutivos, uno detrás delotro, que danprioridadalguión disciplinar previo, luegoderivaneneldiseno espacial a modo de "decoracion" y, finalmente, en una propuesta para el público a modo de “animación”. (ALDEROQUI; PEDERSOLI, 2011, p. 58).
}

Se os museus optam por transformarem-se em locais significativos para seus visitantes, estes têm a tendência de achar ali um ambiente para o encontro do fértil e do diálogo, com histórias que lhes propiciam vivenciar impressões, imaginações, e com experiências transformadoras e essenciais.

Conforme as autoras a "curadoria educativa" preocupa-se com a inclusão da perspectiva educativa nos grupos que estruturam exibições.

Fundamentando-se nas pesquisas de Roberts (1997) apresentam a ideia que o conhecimento é construído socialmente e moldado pelos interesses e concepções de cada indivíduo que aprende. Dessa forma, os museus passam de transmissores unilaterais de conhecimento a edificadores de "novas narrativas", desenvolvidas tanto pelas equipes dos museus como pelos seus visitantes.

Os educadores de museus devem considerar as perspectivas do público durante a investigação das coleções e do patrimônio, pois as mesmas irão tanto interferir na forma como os objetos serão dispostos no espaço quanto determinar quais são as informações necessárias, mais atraentes e os níveis de interpretação para cada audiência.

Ainda com base nas pesquisas de Roberts (1994), Alderoqui e Pedersoli (2011) discutem a função do especialista em aprendizagem e em pesquisas e estudos sobre público de 
museu. Tal educador tem condições de indicar os fatores que influenciam na realização de "experiências significativas" para os visitantes e dessa forma projeta aparatos que põem em jogo a antecipação e negociação entre as "narrativas" estruturadas pelos visitantes e aquelas construídas pelos museus. Para realizar este trabalho é fundamental que possua compreensão do tema da exibição. Isto possibilita tornar mais visível a interpretação sobre a história que a exposição apresenta: desde quem, por que e para quem é importante narrar.

Projetar uma exposição é uma tarefa de equipe, onde cada um deveria poder executar sua função com "paixão" e desde um local que lhe é próprio. A partir desta visão, é importante partir do fato de que o interesse e as necessidades dos visitantes preenchem um lugar central em suas aprendizagens e experiências museais.

Dessa forma, os educadores envolvidos no processo de curadorias devem atualizar-se no conhecimento sobre "estudos de visitantes" e "impacto de museus".

É necessário reconhecer, desde as primeiras fases do processo de design, os temas específicos sobre os quais é importante intervir com o objetivo de ser embasado e dessa forma apresentar as ações museais. Da mesma maneira, é importante questionar-se diversas vezes, durante o desenvolvimento, sobre a relevância dos conteúdos para o público alvo da exibição: sejam eles adultos, crianças, jovens, etc.

Los educadores de museodisenamos permanentemente experiencias educativas, sociales y culturales por las que pasannuestros visitantes. Esasexperiencias, además, se conviertenen parte de sus identidades, y enla base de otras experiências subsiguientes. (ALDEROQUI; PEDERSOLI, 2011, p. 62).

\section{A INTERAÇÃO COMO EXPERIÊNCIA}

Os museus são espaços com uma cultura própria e, neste sentido, oferecem ao público uma forma de interação, com o conhecimento, diferenciada. Sobre tal tema tem se preocupado também o Museo de Las Escuelas de Buenos Aires, Argentina.

EnelMuseo de lasEscuelas utilizamos ladramatizaciónen complemento com otras formas de acercamiento al público, porque consideramos que favorece laaquisición de conceptos complejos y de un tipo de experiência envolvente que permite que nuestros visitantes se sientan más involucrados com nuestro relato, com la historia que les queremos contar. (PUGLIESE, 2012, p. 99).

Uma das experiências que muitos museus oferecem ao seu público-alvo é a interação. Diferentemente dos museus de coleção, os museus denominados interativos apareceram com objetivos pedagógico-didáticos. Neles, o valor da exposição não está restrito aos objetos, mas sim aos fenômenos, processos ou conceitos que intentam comunicar aos 
visitantes por meio da utilização de equipamentos, módulos ou exibidores configurados especialmente para esta finalidade. Estes museus se caracterizam por terem transformado a forma de abordar os conteúdos, seus propósitos e sua razão de existirem, abrindo-se a um público maior formado principalmente pelas crianças, pelos jovens e seus familiares.

Diversas pesquisas sobre educação patrimonial têm evidenciado o potencial destes locais, pois promovem a curiosidade, estimulam, motivam e socializam, sendo esses elementos fundamentais no processo de ensino-aprendizagem. Dessa forma, constatamos que por meio de ações museológicas interativas o indivíduo sente-se à vontade para manipular os objetos, trocar experiências, confrontar informações, sempre tendo como mediador dessas relações os objetos e os propósitos das exposições.

As propostas interativas abrangem um cenário extenso, que envolvem museus para crianças, planetários, museus astronômicos, exposições de arte, história e outras ciências sociais, embora seja no contexto dos museus de ciência e tecnologia onde eles se originaram. Alguns especialistas observam que o antecedente destes museus remonta ao século XVIII, com a criação do Museu do Conservatório de Artes e Ofícios de Paris, cuja função era promover uma instrução profissional aos que se ocupavam das atividades mecânicas.

Conforme Alderoqui e Pedersoli (2011) um dos pressupostos em que se baseiam os museus e exposições interativas é que vivenciar algo é a melhor forma de aprender, e que a "participação ativa" do público é fundamental.

Assim, discorrem que há inúmeros pesquisadores que aprofundam a discussão sobre a relação entre interação e aprendizagem.

\footnotetext{
Esque existe una confusióncomún que equipara manipulaciónoacción motriz [presionarunbotón, tirar una soga o palavanca, girar una manija]conaprendizaje. Esta es una perspectiva reduccionistaderivadadelconductismo, segúnlacualelaprendizajeocurre a partir de laaccióndirecta sobre el mundo exterior y, consecuentemente, de suinteriorización. El sujetoes considerado como una especie de hojaenblanco, cuyaactividad se reduce a internalizar larealidad externa a modo de copia. (ALDEROQUI; PEDERSOLI, 2011, p. 67).
}

Segundo as autoras os eixos centrais associados à aprendizagem construtivista que os educadores de museus deveriam considerar são que a ação fundamental da construção do significado é mental, a aprendizagem é uma atividade social e contextual.

As tecnologias da informação e da comunicação também impactam na transformação e ampliação do conceito de interação, uma vez que atuam em uma "redefinição de tempos", "espaços" e maneiras em que se aprende e conhece. Cada vez mais aumentam os museus que disponibilizam "tours virtuais" por meio de suas exibições. Como visitantes virtuais, é 
possível percorrer pelos quartos e salas, admirar objetos, obras e expositores, acessar os materiais educativos para públicos distintos, consultar a agenda educativa e cultural, assistir vídeos sobre vários assuntos vinculados com os conteúdos e funções do museu (conservação, educação, recreação, conectar-se aos seus documentos e publicações especializadas, comprar objetos das lojas que os mesmos abrigam, dentre as várias ações possíveis).

Dessa forma, considerando a interação a partir destas ações, é possível afirmar que, embora a participação do público em um museu pode ser "ativa" do ponto de vista "motriz", ela não significa necessariamente a compreensão e apropriação do que está ocorrendo. Por outro lado, um indivíduo pode comprometer-se ativamente na elaboração do conhecimento sem que envolva uma ação motora sobre os objetos.

Assim, de acordo com as autoras, é importante redefinir o conceito de interação a partir de uma perspectiva completa, que ultrapasse os reducionismos e identifique o "sujeito" que se compromete nas experiências que o museu lhe proporciona como uma pessoa que pensa, sente e atua ao relacionar-se individual e coletivamente com circunstâncias de conhecimento. Desde esta visão, a concepção de espectador também se transforma, pois já não se pode considerar como um sujeito em branco, como uma "tabula rasa", sim como alguém que, com suas particularidades, edifica aquilo que se lhe mostra.

Ao analisar o tema relativo à relação dos alunos com o espaço físico do museu, inferimos que por se tratar de um espaço diferente da sala de aula, a apropriação do mesmo pelos estudantes é diferenciada, havendo possibilidades de uso mais livre. No entanto, para que não ocorra uma dispersão dos alunos que atrapalhe a exploração das exposições, é muito importante o trabalho do facilitador como orientador da visita. Mas por outro lado ressaltamos a importância da liberdade e da autonomia dos estudantes na exploração dos espaços do museu e incentivando uma forma de interação diferenciada do que ocorre na sala de aula.

No que se relaciona às perspectivas educacionais em museus, Marandino (2005) aponta duas abordagens educacionais desenvolvidas nesses espaços. A primeira dessas abordagens por ela apontada é denominada "positivista ou realista", entende epistemologicamente o conhecimento como parte exterior ao aprendiz, como um corpo de conhecimento absoluto nele mesmo que é definido na medida em que pode ser observado, medido e objetivado. A segunda, "construtivista", define o conhecimento como algo construído por meio da interação do aprendiz com o ambiente social e, neste caso, a subjetividade é parte desta construção. 
Com o objetivo de investigarmos a relação entre o público e os objetos das exposições museais devemos levar em conta a "brevidade do tempo", ou seja, os poucos minutos que cada visitante dedica-se a um objeto, a um assunto.

Conforme Marandino (2005, p. 166), “a especificidade do museu está relacionada a elementos como o lugar, o tempo e a importância dos objetos". No que se refere ao tempo, apesar de ser fundamental para as estratégias de comunicação, a autora enfatiza "ele é muito breve se considerarmos os minutos que cada visitante concede a um objeto, a um tema". Segundo ela este "tempo" é determinado tanto pela concepção da exposição como pelo animador/mediador da mesma.

Outra peculiaridade do museu indicada pela autora seria o lugar, pensado como um caminho aberto. "Nele, o visitante é geralmente voluntário e não fica preso, sendo cativado pela exposição durante seu percurso" (MARANDINO, 2005).

As exposições têm deixado de ser uma sequencia de temas independentes e a apropriação da mesma acontece a partir de seu trajeto, com "ambientação", inserção no espaço e cenário criados.

Marandino (2005) ao trazer o tema do "discurso museal", lembra o fato de o mesmo se apoiar nos objetos, sendo estes fontes de conhecimento que permitem a interação. Conforme a autora (IDEM, 167) "os objetos permitem ao visitante se sensibilizar, se apropriar e favorecer sua compreensão [...] para uma análise pessoal e para discutir com os outros visitantes, com os animadores, com os professores".

A discussão que buscamos proceder neste texto ganha a sua importância, sobretudo, quando articuladas às preocupações de como os indivíduos conhecem e buscam, de distintas maneiras, projetar as "experiências" para os diferentes tipos de mostras, exposições e atividades educativas nos museus.

\section{CONSIDERAÇÕES FINAIS}

Se nos anos 1990 a Museologia estabeleceu-se como um campo disciplinar (específico das ciências sociais), no século XXI é possível afirmar que a Museologia se encontra consolidada como campo um transdisciplinar que se empenha na gestão da memória, na utilização da herança patrimonial e à investigação da relação específica entre o ser humano e a realidade. Neste aspecto, alguns objetos são deslocados, ou seja, musealisados para serem preservados e utilizados com fins de conhecimento, sendo-lhes concedidas novas significações. 
Finalmente, a educação em museus é uma prática que vem se consolidando no campo educacional, tanto por uma prática educacional estabelecida a partir das instituições museais, mas também devido ao crescimento do número de trabalhos acadêmicos que se dedicam ao tema.

\section{REFERÊNCIAS}

ALDEROQUI, Silvia et al. Los visitantes como patrimonio: el museo de las escuelas. Buenos Aires, 2012, 157p.

; PEDERSOLI, Constanza. La educación en los museos: de los objetos a los visitantes. Buenos Aires: Paidós, 2011, 272p.

BARRETTO, Margarita. Turismo e legado cultural: as possibilidades do planejamento. 3 . ed. Campinas: Papirus, 2002.

CARRILLO, Isabel et al. Los museus pedagógicos y la proyección cívica del patrimônio educativo. Gijón, Asturias: TREA, 2011, 191p.

CEPEDA, Sofía Marín; LÓPEZ, Sara Pérez. Programas singulares de educación patrimonial: investigar para innovar. In: MERILLAS, Olaia Fontal (coord). La educación patrimonial: del patrimonio a las personas. Gijón, Asturias: TREA, 2013, 143p.

DEXTER LORD, G; LORD, B. La planificación de exposiciones. Actas de las Primeras Jornadas de Formación Museológica, Museos y planificación. Estrategias de Futuro, Secretaría General Técnica, Ministerio de Cultura, Madrid, maio, 2006. Disponível em: <http://mecd.gob.es>. Acesso em: 10 jul. 2015.

MARANDINO, Martha. Enfoques de Educação e Comunicação nas Bioexposições de Museus e Ciências. Revista Brasileira de Pesquisa em Educação em Ciências, São Paulo, v. 3, n. 1, maio, 2003. Disponível em: <http://revistas.if.usp.br/rbpec/article/view/162>. Acesso em: 05 jul. 2015.

. Museus de Ciências como espaços de educação. In: Figueiredo, Betânia Gonçalves; Vidal, Diana Gonçalves (orgs). Museus, dos gabinetes de curiosidades ao museu moderno. Belo Horizonte: Argumentum, 2005, 239p.

MARTINS, Luciana Conrado. A constituição da educação em museus: o funcionamento do dispositivo pedagógico museal por meio de um estudo comparativo entre museus de artes plásticas, ciências humanas e ciência e tecnologia. 2011. 390f. Tese (Doutorado em Educação) - Faculdade de Educação, Universidade de São Paulo, São Paulo.

MERILLAS, Olaia Fontal. La educación patrimonial: teoría y práctica en el aula, el museo e internet. Gijón, Asturias: TREA, 2013, 303p.

PUGLIESE, Mercedes. Dramas: experiencias de visitas teatralizadas. ALDEROQUI, Silvia et al. Los visitantes como patrimonio: el museo de las escuelas. Buenos Aires, 2012, 157p. 
ROBERTS, Lisa. From knowledge to narrative: educators and the changing museum. Smithsonian Institution Press, Washington, 1997.

Educators on exhibition teams: a new role, a new era. Journal of Museum Education, Washington, n 3, XIX, 1994. Disponível em: 〈http://museumeducation.info〉. Acesso em: 30 jul. 2015.

VALENTE. Maria Esther Alvarez. Museus de Ciências e Tecnologia no Brasil: uma história da museologia entre as décadas de 1950-1970. 2008. 276f. Tese (Doutorado em Ciência) - Instituto de Geociências, Universidade Estadual de Campinas. 